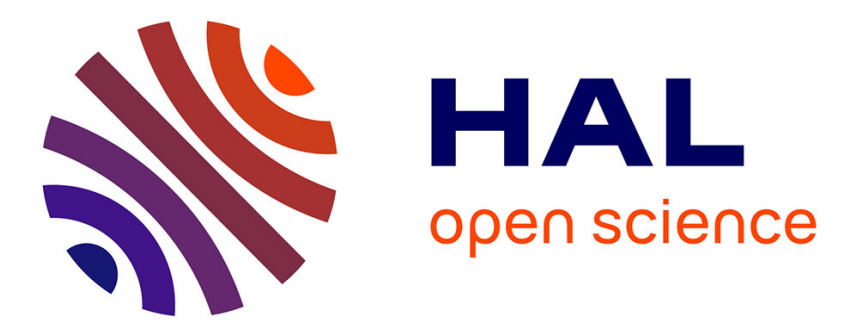

\title{
Comments on "State observation of a fixed-bed reactor based on reduced bilinear models"
}

\author{
Hugues Rafaralahy, Michel Zasadzinski, Mohamed Boutayeb, Mohamed \\ Darouach
}

\section{- To cite this version:}

Hugues Rafaralahy, Michel Zasadzinski, Mohamed Boutayeb, Mohamed Darouach. Comments on "State observation of a fixed-bed reactor based on reduced bilinear models". International Journal of Systems Science, 1996, 27 (3), pp.349-351. hal-00098272

\section{HAL Id: hal-00098272 \\ https://hal.science/hal-00098272}

Submitted on 25 Sep 2006

HAL is a multi-disciplinary open access archive for the deposit and dissemination of scientific research documents, whether they are published or not. The documents may come from teaching and research institutions in France or abroad, or from public or private research centers.
L'archive ouverte pluridisciplinaire HAL, est destinée au dépôt et à la diffusion de documents scientifiques de niveau recherche, publiés ou non, émanant des établissements d'enseignement et de recherche français ou étrangers, des laboratoires publics ou privés. 


\title{
Comments on "State observation of a fixed-bed reactor based on reduced bilinear models"
}

\author{
H. RAFARALAHY, M. ZASADZINSKI, M. BOUTAYEB and M. DAROUACH ${ }^{\dagger}$
}

\begin{abstract}
In this note, we point out that the proof of the convergence of the bilinear systems observer proposed by Hua (1993) is erroneous. Furthermore, the proposed existence conditions are not sufficient as it was claimed. To overcome these difficulties, we propose a straigthforward proof of the observer's convergence based on Lyapunov stability and we deduce sufficient existence conditions.
\end{abstract}

\section{Introduction}

In a recent paper, X.-M. Hua (1993) presented a new bilinear observer design via poleplacement technique. This observer is used to estimate the temperature and the concentration profiles of a fixed-bed reactor approximated as bilinear system through orthogonal collocation. The proposed approach seems to be attractive since it can be applied to a large class of bilinear systems whereas the observers proposed by Hara and Furuta (1976), Funahashi (1979) or Derese et al. (1979), fail. Unfortunately, the proof of the convergence of this observer, based on Lyapunov stability, is erroneous. In addition, we demonstrate, via a counter-example, that the given existence conditions are not sufficient. Thus, we propose a simple proof and we deduce sufficient existence conditions of the observer which are stronger than those given by Hua.

\section{Preliminaries}

Consider the following continuous-time bilinear system

$$
\begin{gathered}
\dot{x}(t)=A x(t)+\sum_{i=1}^{p} N_{i} x(t) u_{i}(t)+B u(t) \\
y(t)=C x(t)
\end{gathered}
$$

where $\mathrm{x}(\mathrm{t}) \in \mathfrak{R}^{\mathrm{n}}, \mathrm{y}(\mathrm{t}) \in \mathfrak{R}^{\mathrm{m}}$ and $\mathrm{u}(\mathrm{t})=\left[\mathrm{u}_{1}(\mathrm{t}) \ldots \mathrm{u}_{\mathrm{p}}(\mathrm{t})\right]^{\mathrm{T}} \in \mathfrak{R}^{\mathrm{p}}$ are state, output and input vectors respectively. The matrices $\mathrm{A}, \mathrm{N}_{\mathrm{i}}(\mathrm{i}=1 \ldots \mathrm{p}), \mathrm{B}$ and $\mathrm{C}$ are constant and of appropriate dimensions. Assume that the inputs of (1) are bounded, i.e. $u(t) \in \Omega$ where

$$
\Omega=\left\{\mathrm{u}(\mathrm{t}) / \mathrm{u}_{\mathrm{i}, \min } \leq \mathrm{u}_{\mathrm{i}}(\mathrm{t}) \leq \mathrm{u}_{\mathrm{i}, \max } \text { for all } \mathrm{t} \text {, and } \mathrm{i}=1 \ldots \mathrm{p}\right\}
$$

The full-order state observer of (1) and (2) is of the following form

$$
\dot{\hat{x}}(t)=A \hat{x}(t)+\sum_{i=1}^{p} N_{i} \hat{x}(t) u_{i}(t)+B u(t)+G_{0}(y(t)-C \hat{x}(t))+\sum_{i=1}^{p} G_{i}(y(t)-C \hat{x}(t)) u_{i}(t)
$$

where $\hat{\mathrm{x}}(\mathrm{t}) \in \mathfrak{R}^{\mathrm{n}}$ is the state estimate. The observation error is defined by

† CRAN-ACS CRNS URA 821, Université Henri Poincaré-Nancy I, 186 rue de Lorraine, 54400 Cosnes-et-Romain, FRANCE. 


$$
e(t)=\hat{x}(t)-x(t)
$$

which satisfies the following dynamical equation

where

$$
\dot{e}(t)=\Gamma_{0} e(t)+\sum_{i=1}^{p} \Gamma_{i} e(t) u_{i}(t) \quad e(0)=e_{0}
$$

The main objective is to find suitable observer's gain matrices $G_{0}$ and $G_{i}$ such that the observation error approaches zero asymptotically regardless of the initial error.

The two-step design procedure of the bilinear state observer, proposed by Hua, is given by

Step 1 : choose $G_{i}$ such that $\Gamma_{i}$ are Hurwitz, $i=1 \ldots p$,

Step 2 : choose $G_{0}$ such that $\bar{\Gamma}_{0}$ is Hurwitz, where $\bar{\Gamma}_{0}=\mathrm{F}-\mathrm{G}_{0} \mathrm{C}$ and $\mathrm{F}=\mathrm{A}+\sum_{\mathrm{i}=1}^{\mathrm{p}} \Gamma_{\mathrm{i}} \mathrm{u}_{\mathrm{i}, \min }$.

The sufficient existence conditions proposed by Hua are

(ia) the pair $(\mathrm{F}, \mathrm{C})$ is observable,

(iia) and the pairs $\left(\mathrm{N}_{\mathrm{i}}, \mathrm{C}\right)$ are observable, $\mathrm{i}=1 \ldots \mathrm{p}$

which correspond to the observers convergence conditions (ib) and (iib) given by Hua supposedly sufficient

(ib) $\bar{\Gamma}_{0}$ is Hurwitz,

(iib) and $\Gamma_{i}$ are Hurwitz, $i=1 \ldots$.

In the following section, we pointed out that the proof proposed by Hua is found to be incorrect and we demonstrate, via a counter-example, that the given existence conditions are not sufficient.

\section{Comments on the proof of the observers convergence}

In order to investigate the stability of the error dynamics, Hua used the Lyapunov stability approach and the fact that, for an observable pair $(F, C)$, there exists a gain matrix $G_{0}$ such that $\bar{\Gamma}_{0}=\mathrm{F}-\mathrm{G}_{0} \mathrm{C}$ is Hurwitz. Therefore, given a symmetric positive-definite matrix $\mathrm{Q}$, there exists a symmetric positive-definite matrix $\mathrm{P}$ which satisfies the following equation

$$
\mathrm{P}\left(\mathrm{F}-\mathrm{G}_{0} \mathrm{C}\right)+\left(\mathrm{F}-\mathrm{G}_{0} \mathrm{C}\right)^{\mathrm{T}} \mathrm{P}=-\mathrm{Q}<0
$$

which is equivalent to

$$
\mathrm{P} \Gamma_{0}+\Gamma_{0}^{\mathrm{T}} \mathrm{P}+\sum_{\mathrm{i}=1}^{\mathrm{p}}\left(\mathrm{P} \Gamma_{\mathrm{i}}+\Gamma_{\mathrm{i}}^{\mathrm{T}} \mathrm{P}\right) \mathrm{u}_{\mathrm{i}, \min }=-\mathrm{Q}<0
$$

Let $\mathrm{V}(\mathrm{e})$ be a Lyapunov function candidate

$$
\mathrm{V}(\mathrm{e})=\mathrm{e}^{\mathrm{T}} \mathrm{Pe}
$$

where $\mathrm{P}$ is a symmetric positive-definite matrix. Differentiation of $\mathrm{V}(\mathrm{e})$ yields

$$
\dot{\mathrm{V}}(\mathrm{e})=\mathrm{e}^{\mathrm{T}}\left(\mathrm{P} \Gamma_{0}+\Gamma_{0}^{\mathrm{T}} \mathrm{P}\right) \mathrm{e}+\sum_{\mathrm{i}=1}^{\mathrm{p}} \mathrm{e}^{\mathrm{T}}\left(\mathrm{P} \Gamma_{\mathrm{i}}+\Gamma_{\mathrm{i}}^{\mathrm{T}} \mathrm{P}\right) \mathrm{eu}_{\mathrm{i}}
$$

In his paper, Hua concluded, from equation (7), that relations (10) and (11) hold

$$
\mathrm{P} \Gamma_{i}+\Gamma_{i}^{\mathrm{T}} \mathrm{P}<0 \text { for } \mathrm{i}=1, \ldots, \mathrm{p}
$$




$$
\text { and } \mathrm{P} \Gamma_{0}+\Gamma_{0}^{\mathrm{T}} \mathrm{P}<0
$$

This is equivalent to the existence of an unique solution $\mathrm{P}$ which satisfies simultaneously the following set of Lyapunov equations

$$
\begin{gathered}
P \Gamma_{i}+\Gamma_{i}^{T} \mathrm{P}=-\mathrm{Q}_{\mathrm{i}} \text { for } \mathrm{i}=1, \ldots, \mathrm{p} \\
\text { and } \mathrm{P} \Gamma_{0}+\Gamma_{0}^{\mathrm{T}} \mathrm{P}=-\mathrm{Q}_{0}
\end{gathered}
$$

where $\mathrm{Q}_{0}$ and $\mathrm{Q}_{\mathrm{i}}$ are symmetric positive-definite matrices. With the following counter-example, we demonstrate that if relation (7) holds, relations (10a-b) and (11a-b) are not necessarily satisfied. Indeed, consider the following stable matrices $\Gamma_{0}$ and $\Gamma_{1}$

$\Gamma_{0}=\left[\begin{array}{ll}g_{011} & g_{012} \\ g_{021} & g_{022}\end{array}\right], \Gamma_{1}=\left[\begin{array}{ll}g_{111} & g_{112} \\ g_{121} & g_{122}\end{array}\right]$, with $g_{011}<0, g_{012}>0, g_{021}<0, g_{022}=0, g_{111}<0$, $\mathrm{g}_{112}<0, \mathrm{~g}_{121}>0$ and $\mathrm{g}_{122}=0$. Assume that $\mathrm{u}_{\min }=1, \mathrm{~g}_{012}<-\mathrm{g}_{112}$ and $\mathrm{g}_{021}>-\mathrm{g}_{121}$, then $\left(\Gamma_{0}+\mathrm{u}_{\min } \Gamma_{1}\right)$ is stable and there exists a symmetric positive-definite $\mathrm{P}$ matrix such that (7) holds

$$
\mathrm{P}=\left[\begin{array}{ll}
\mathrm{p}_{1} & \mathrm{p}_{2} \\
\mathrm{p}_{2} & \mathrm{p}_{3}
\end{array}\right] \text {, with } \mathrm{p}_{1}>0\left(\mathrm{p}_{3}>0\right) \text { and } \mathrm{p}_{1} \mathrm{p}_{3}>\mathrm{p}_{2}^{2}
$$

Then the constraint $\left(-\frac{\mathrm{g}_{011}}{\mathrm{~g}_{021}} \mathrm{p}_{1}<\mathrm{p}_{2}<0\right)$ is necessary to obtain $\mathrm{P} \Gamma_{0}+\Gamma_{0}^{\mathrm{T}} \mathrm{P}<0$ while the constraint $\left(0<\mathrm{p}_{2}<-\frac{\mathrm{g}_{111}}{\mathrm{~g}_{121}} \mathrm{p}_{1}\right)$ is necessary to achieve $\mathrm{P} \Gamma_{1}+\Gamma_{1}^{\mathrm{T}} \mathrm{P}<0$. Unfortunately, these two constraints cannot be satisfied simultaneously. Hence, the implication used by Hua in the observer convergence proof does not hold.

\section{Comments on the existence conditions}

Consider the numerical example worked out in Hua

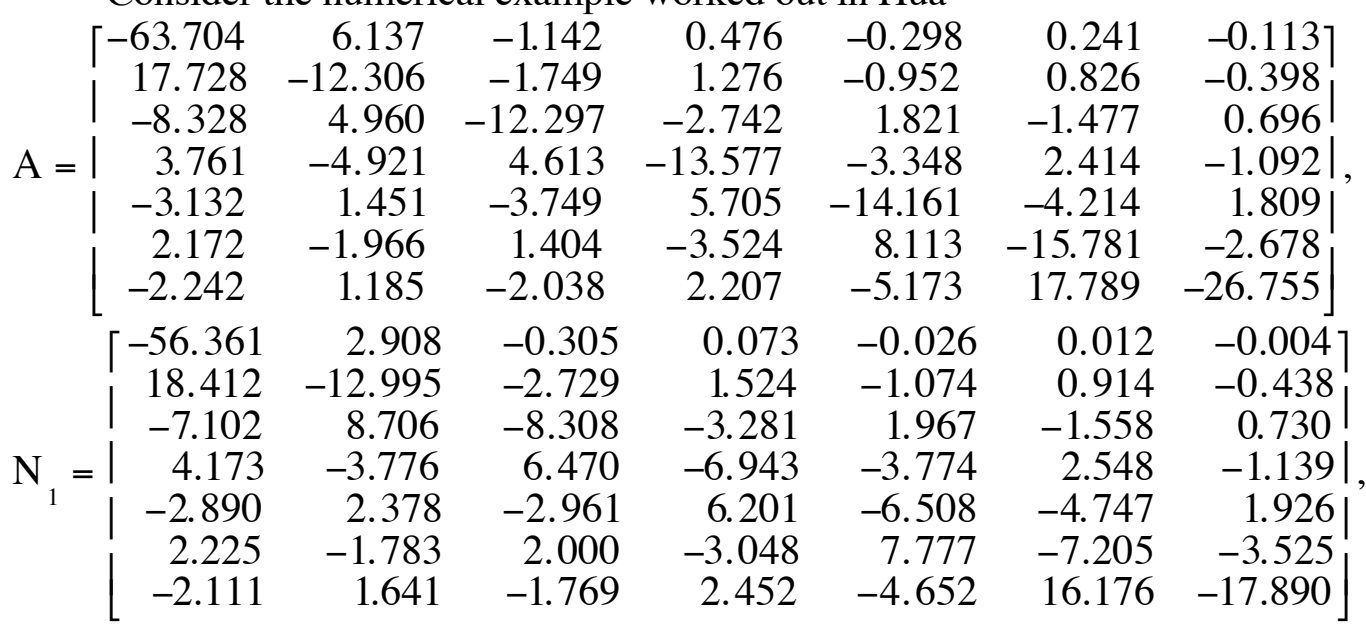

$\mathrm{B}^{\mathrm{T}}=\left[\begin{array}{lllllll}-9.722 & -3.057 & 6.983 & 5.236 & 3.455 & 1.866 & 1.694\end{array}\right], \mathrm{C}=\left[\begin{array}{lllllll}0 & 0 & 0 & 0 & 0 & 0 & 1\end{array}\right]$ and $\mathrm{u}_{\min }=-0.3, \mathrm{u}_{\max }=0.25 . \mathrm{N}_{1}$ being stable, $\mathrm{G}_{1}$ can be chosen as $\mathrm{G}_{1}=0$ i.e. $\Gamma_{1}=\mathrm{N}_{1}$. 
The pair $\left(A+u_{\min } \Gamma_{1}, C\right)$ being observable, we can choose a gain matrix $G$ such that $\left(A+u_{\min } \Gamma_{1}-G C\right)$ is stable. Selecting the eigenvalues of $\left(A+u_{\min } \Gamma_{1}-G C\right)$ as $\{-10,-5,-2,-3 \pm i,-1 \pm i\}$, one obtains, by pole-placement techniques, the gain matrix

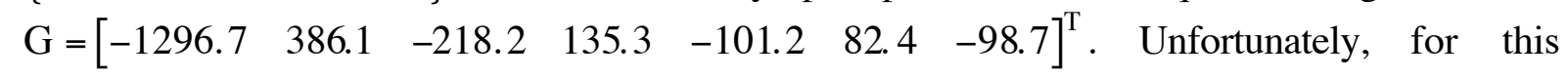
choice of gain matrix $G$, the observation error is not stable for all values of $\mathrm{u} \in[-0.29 ;-0.12] \subset\left[\mathrm{u}_{\min } ; \mathrm{u}_{\max }\right]$. We can conclude that even if conditions (ia-b) and (iia-b) in Hua are satisfied, i.e. matrices $\Gamma_{0}-\mathrm{GC}$ and $\Gamma_{1}$ are stable, the observer convergence is not necessarily guaranteed. This means that these conditions are not sufficient.

\section{Convergence analysis and existence conditions}

Before stating the convergence of the observer, let introduce the following notation

$$
\text { for all } u_{i}(t) \in \Omega, u_{i}(t)=u_{i, \min }+\varepsilon_{i}(t)
$$

where $\varepsilon_{i}(t) \geq 0$ for all $t$. The observation error can be rewritten as follows

$$
\dot{e}(t)=\left(\Gamma_{0}+\sum_{i=1}^{p} \Gamma_{i} u_{i, \min }\right) e(t)+\sum_{i=1}^{p} \Gamma_{i} e(t) \varepsilon_{i}(t)
$$

or equivalently

$$
\dot{\mathrm{e}}(\mathrm{t})=\left(\bar{\Gamma}_{0}+\sum_{\mathrm{i}=1}^{\mathrm{p}} \Gamma_{\mathrm{i}} \varepsilon_{\mathrm{i}}(\mathrm{t})\right) \mathrm{e}(\mathrm{t})
$$

where $\bar{\Gamma}_{0}$ and $\Gamma_{\mathrm{i}}$ are Hurwitz and defined above.

In this form, the problem is reduced to the stability analysis of linear system with timevarying structured uncertainties. A sufficient condition guaranteeing the asymptotic stability of (14) was given in Mansour (1988) as follows.

The observation error (14) is asymptotically stable if

(iii) $\mu\left(\bar{\Gamma}_{0}\right)<0$ and $\mu\left(\Gamma_{i}\right)<0$ for all $\Gamma_{i}$, where $\mu($.) denotes the matrix measure of (.)

(Desoer 1975).

Note that the numerical example worked out in Hua verifies this condition.

A less conservative version of this condition can be stated as follows

(iv) $\mu\left(\bar{\Gamma}_{0}\right)<0$ and $\mu\left(\bar{\Gamma}_{0}\right)+\sum_{i=1}^{p} \mu\left(\Gamma_{i}\right) \tilde{\varepsilon}_{i}<0$ where $\tilde{\varepsilon}_{i}=u_{i \max }-u_{i \min }$ if $\mu\left(\Gamma_{i}\right)>0$ otherwise $\tilde{\varepsilon}_{i}=0$.

The proof of this condition is obvious by chosing $\mathrm{V}(\mathrm{e})=\mathrm{e}^{\mathrm{T}} \mathrm{e}$ as Lyapunov function candidate. Notice that the class of matrix pairs $(A, C)$ for which there exists a gain matrix $G$ such that $\mu(\mathrm{A}-\mathrm{GC})<0$ neither includes nor is included by the set of observable pairs (Mori et al. 1983) but is only a subset of the detectable pairs. Then the observer design cannot be reduced to unconstrained pole-placements as proposed by Hua, the convergence conditions (iii) or (iv) are stronger than (ib) and (iib). 


\section{References}

Derese, I., STEVEns, P., Noldus, E., 1979, 'Observers for bilinear systems with bounded input', International Journal of Systems Science, 10, 649-668.

DESOER, C. A.,VIDYASAGAR, M., 1975, Feedback systems: input-output properties, (Academic Press - New York, San Francisco, London).

FUNAHASHI, Y., 1979, 'Stable state estimator for bilinear systems', International Journal of Control, 29, 181-188.

HARA, S., FURUTA, K., 1976, 'Minimal order state observers for bilinear systems', International Journal of Control, 24, 705-718.

HUA, X.-M., 1993, 'State observation of a fixed-bed reactor based on bilinear models', International Journal of Systems Science, 24, 2075-2095.

MANSOUR, M., 1988, 'Sufficient conditions for the asymptotic stability of interval matrices', International Journal of Control, 47, 1973-1974.

MORI, T., NOLDUS, E., KUWAHARA, M., 1983, 'A way to stabilise linear systems with delayed state', Automatica, 19, 571-573. 